\title{
КИНЕТИКА И МЕХАНИЗМ ИЗМЕЛЬЧЕНИЯ КОНВЕРСИОННОГО КАРБОНАТА КАЛЬЦИЯ
}

\author{
(C) 2018 Л. В. Рудакова ${ }^{1}$, С. И. Нифталиев ${ }^{2}$, Е. С. Натарова ${ }^{1}$ \\ ${ }^{1}$ Воронежский государственный медицинский университет им. Н. Н. Бурденко, \\ ул. Студенческая, 10, 394036 Воронеж, Россия \\ ${ }^{2}$ Воронежский государственный университет инженерных технологий, \\ пр. Революиии, 19, 394036 Воронеж, Россия \\ e-mail: natarovaekaterina@yandex.ru
}

Поступила в редакцию 21.02.2018

\begin{abstract}
Аннотация. Определены основные закономерности протекания процесса измельчения конверсионного карбоната кальция - побочного продукта производства нитроаммофоски - в вибрационной мельнице. Кинетика измельчения подчиняется уравнению первого порядка. Наблюдается линейная зависимость между относительным содержанием неизмельченных фракций и временем измельчения. На основании кинетических кривых получено уравнение для расчета удельной скорости измельчения от размера частиц конверсионного карбоната кальция.
\end{abstract}

Ключевые слова: конверсионный карбонат кальция, измельчение, скорость процесса, кинетика.

DOI: https://doi.org/10.17308/kcmf.2018.20/516

\section{ВВЕДЕНИЕ}

Конверсионный карбонат кальция - побочный продукт производства комплексного минерального удобрения - нитроаммофоски, процесс получения которой основан на азотнокислом разложении апатитового концентрата с выделением избытка нитрата кальция и дальнейшей его кристаллизацией и конверсией в карбонат кальция и аммиачную селитру. В РФ производят нитроаммофоску несколько крупных предприятий - ПАО «Акрон» (г. Великий Новгород), АО «Минудобрения» (г. Россошь), ПАО «Дорогобуж» (г. Дорогобуж), ОАО «Уралхим» (г. Кирово-Чепецк). Объёмы конверсионного карбоната кальция суммарно превышают 1 млн. т в год. В связи с этим остро стоит вопрос его дальнейшего применения. Перспективное направление переработки конверсионного карбоната кальция применение в качестве дисперсного неорганического наполнителя в полимерных композиционных материалах (ПКМ).

Конверсионный карбонат кальция по внешнему виду представляет собой сыпучий порошок белого цвета с незначительными вкраплениями видимых невооруженным взглядом зерен темного цве- та. Основная масса частиц конверсионного карбоната кальция имеет размеры $30 . .150$ мкм [1], что не удовлетворяет требованиям по дисперсности наполнителей ПКМ [2]. Для получения кондиционного продукта и его использования в качестве наполнителя необходимым является доизмельчение мела.

Важнейшей характеристикой процесса диспергирования, которая определяет производительность, выбор и параметры работы измельчающего оборудования в производственных условиях, является скорость измельчения. Поэтому целью работы являлось определение основных кинетических закономерностей процесса измельчения конверсионного карбоната кальция.

\section{ЭКСПЕРИМЕНТАЛЬНАЯ ЧАСТЬ}

Измельчение конверсионного карбоната кальция проводили с использованием лабораторной ролико-кольцевой вибрационной мельницы VM4. Масса одновременно загружаемой пробы составляла $100 \pm 5$ г, величина энергонапряженности 11 кВТ/ кг. При длительности измельчения более 5 минут происходил существенный разогрев мелющей гарнитуры и, соответственно, загруженной в мельни- 
цу пробы, поэтому использовали схему: измельчение - охлаждение пробы (30 мин) - дальнейшее измельчение.

Для изучения кинетики и механизма измельчения пробы конверсионного карбоната кальция отбирали через каждую минуту, затем определяли фракционный состав пробы.

Анализ дисперсного состава проводился лазерно-дифракционным методом на анализаторе Microtrac S3500 фирмы «Microtrac Inc» в режиме диспергирования пробы в водной среде.

Исследование кинетики измельчения было проведено методом оценки изменения фракционного состава материала в процессе его разрушения.

\section{РЕЗУЛЬТАТЫ ИССЛЕДОВАНИЯ И ИХ ОБСУЖДЕНИЕ}

В результате исследований получены зависимости изменения фракционного состава конверсионного карбоната кальция от продолжительности измельчения (табл. 1), рассчитаны скорости процесса по каждой фракции (табл. 2).
Видно, что измельчение протекает крайне интенсивно в первоначальный момент времени $(t=0-$ 1 мин). Максимальная скорость измельчения достигается для фракций 50-75, 75-100, 100-150 мкм и составляет 14.5, 13.5 и 17.8 \%/мин соответственно. В то же время, наиболее крупные частицы размером 150-200 мкм и >200 мкм имеют существенно более низкую скорость измельчения: 7.2 и 3.0 \%/ мин. Таким образом, быстрое разрушение частиц карбоната кальция в пределах 50-150 мкм в совокупности с преобладанием данного класса в составе исходного продукта (более 68 \%) лимитирует общий темп диспергирования. В мелких фракциях скорость измельчения отрицательна, что свидетельствует о том, что в них происходит предпочтительно накопление продуктов разрушения более крупных фракций. Быстрее всего в первоначальный период растет содержание частиц размером $>5$ мкм (-22.8\%/мин), существенно меньше скорость накопления в фракциях 5-10, 10-20 и 20-30 мкм (9.3, 11.7 и $5.4 \%$ мин). После минутного измельчения содержание частиц размером $<5$ мкм возрастает с

Таблица 1. Изменение дисперсного состава конверсионного карбоната кальция по фракциям в процессе измельчения

[Table 1. Change in the dispersion composition of conversion calcium carbonate by fractions during the grinding process]

\begin{tabular}{|c|c|c|c|c|c|c|c|c|c|c|}
\hline \multirow[t]{2}{*}{$\begin{array}{l}\text { Время измельчения, } t, \text { мин } \\
\text { [Time of grinding, } t, \text { minutes] }\end{array}$} & \multicolumn{10}{|c|}{$\begin{array}{c}\text { Процентное содержание частиц во фракциях (в мкм), } R_{\mathrm{d}} \% \\
\left.\text { [Percentage of particles in fractions }(\mu \mathrm{m}), R_{\mathrm{d}} \%\right]\end{array}$} \\
\hline & $<5$ & $5-10$ & $10-20$ & $20-30$ & $30-50$ & $50-75$ & $75-100$ & $100-150$ & $150-200$ & $>200$ \\
\hline 0 & 0.1 & 0.3 & 1.3 & 2.5 & 12.6 & 25.8 & 19.7 & 22.9 & 9.1 & 5.7 \\
\hline 1 & 30.0 & 9.6 & 13.0 & 7.9 & 12.5 & 11.3 & 6.2 & 5.1 & 1.9 & 2.5 \\
\hline 2 & 36.6 & 13.4 & 12.6 & 7.3 & 11.7 & 9.1 & 3.8 & 2.6 & 1.0 & 1.9 \\
\hline 3 & 44.5 & 13.8 & 12.2 & 9.0 & 7.9 & 6.8 & 1.8 & 1.7 & 0.7 & 1.6 \\
\hline 4 & 50.2 & 13.4 & 12.8 & 7.1 & 8.7 & 4.1 & 1.4 & 1.0 & 0.3 & 1.0 \\
\hline 5 & 48.2 & 16.4 & 11.3 & 6.3 & 8.3 & 4.7 & 1.7 & 1.3 & 0.5 & 1.3 \\
\hline 10 & 48.1 & 14.8 & 12.6 & 7.4 & 8.3 & 4.3 & 1.8 & 1.3 & 0.5 & 0.9 \\
\hline 15 & 47.5 & 9.7 & 15.2 & 9.6 & 10.0 & 4.0 & 1.3 & 1.0 & 0.4 & 1.3 \\
\hline 30 & 45.0 & 13.4 & 16.6 & 9.8 & 8.7 & 3.4 & 1.1 & 0.9 & 0.3 & 0.8 \\
\hline
\end{tabular}

Таблица 2. Изменение скорости измельчения конверсионного карбоната кальция

[Table 2. Change in the Rate of Crushing Conversion Calcium Carbonate]

\begin{tabular}{|c|c|c|c|c|c|c|c|c|c|c|c|}
\hline \multirow{2}{*}{$\begin{array}{c}\text { Bремя измельчения, } t, \text { мин } \\
\text { [Time of grinding, } t, \text { minutes] }\end{array}$} & \multicolumn{8}{|c|}{ Увеличение/уменьшение фракций (мкм), \% / мин } \\
\cline { 2 - 13 } & $<5$ & $5-10$ & $10-20$ & $20-30$ & $30-50$ & $50-75$ & $75-100$ & $100-150$ & $150-200$ & $>200$ \\
\hline 1 & 29.90 & 9.30 & 11.70 & 5.40 & -0.10 & -14.50 & -13.50 & -17.80 & -7.20 & -3.20 \\
\hline 2 & 7.60 & 0.40 & -3.00 & -2.00 & -1.20 & -0.60 & -0.80 & -1.20 & 1.00 & -0.20 \\
\hline 3 & 3.40 & 0.60 & -2.40 & 2.40 & -1.80 & -2.60 & -0.80 & 0.40 & 0.40 & 0.40 \\
\hline 4 & 5.40 & -0.60 & -1.20 & 1.00 & 2.40 & -6.60 & 0.20 & 0.00 & -0.40 & -0.20 \\
\hline 5 & -3.00 & 5.80 & -2.40 & -0.80 & -0.20 & 0.40 & 0.00 & 0.00 & 0.00 & 0.20 \\
\hline 10 & -0.02 & -0.32 & 0.26 & 0.22 & 0.00 & -0.08 & 0.02 & 0.00 & 0.00 & -0.08 \\
\hline 15 & -0.12 & -1.02 & 0.52 & 0.44 & 0.34 & -0.06 & -0.10 & -0.06 & -0.02 & 0.08 \\
\hline 30 & -0.17 & 0.25 & 0.09 & 0.01 & -0.09 & -0.04 & -0.01 & -0.01 & -0.01 & -0.03 \\
\hline
\end{tabular}


0.1 до $30.0 \%$, размером 5-10 мкм с 0.3 до $9.6 \%$, 10-20 мкм с 1.3 до $13.0 \%$, несколько меньший прирост наблюдается в фракции 20-30 мкм - с 2.5 до $7.9 \%$. Суммарное содержание продукта с размером частиц до 30 мкм возрастает с 4.2 до $60.5 \%$, то есть более чем в 14 раз.

Для промежуточной фракции 30-50 мкм скорость изменения близка к нулю и её содержание остается практически постоянным (12.6-12.5 \%). Это можно объяснить с нескольких позиций. С одной стороны, возможно, что процессы накопления и разрушения в данной фракции происходят с одинаковой интенсивностью и, соответственно, их скорости уравновешиваются. С другой стороны, вероятно, что разрушающих усилий, создаваемых в мельнице, недостаточно для диспергирования частиц с размерами данной фракции, и, в тоже время, разрушенные частицы верхних классов (более 50 мкм) переходят в более мелкие классы (менее 30 мкм), т. е. процесс измельчения является селективным по размеру продуктов разрушения. Исходя из факта уменьшения скорости накопления с увеличением размера частиц, близкая к нулю скорость изменения размеров частиц фракции 30-50 мкм связана, именно, с селективностью измельчения. Отсутствие измельчения частиц с размерами от 30 до 50 мкм, по-видимому, обусловлено тем, что они при стесненном движении в рабочем объеме мельницы попадают в зазоры между более крупными частицами и непосредственного ударного воздействия измельчающей гарнитуры.

Однако после минуты измельчения характер процесса меняется - интенсивность диспергирования резко снижается, что выражается в снижении скоростей накопления мелких фракций и разрушения крупных. Содержание крупных фракций, в составе которых присутствуют частицы с размерами свыше 50 мкм, при увеличении продолжительности измельчения с 1 до 30 мин снижается с 27.0 до $6.5 \%$ с общей интенсивностью, аналогичной минутному измельчению. Необходимо отметить, что полного измельчения наиболее крупных частиц размером $>150$ мкм не достигается и при 30 минутах измельчения, содержание фракции 150-200 мкм и 200 мкм составляет 0.3 и $0.8 \%$ соответственно.

Количество частиц размером 30-50 мкм в течение всего времени измельчения остается практически постоянным в интервале 7.9-12.5\%, это говорит о том, что разрушения частиц не происходит, наблюдаются близкие к нулю и переменные по знаку скорости.
При увеличении времени обработки до 510 минут, аналогично фракции 30-50 мкм, не происходит заметного изменения размеров частиц в интервале 10-20 мкм и 20-30 мкм. Выраженное накопление частиц в данных фракциях в первый момент измельчения ( $t=1$ мин) прекращается, и продукты разрушения верхних классов начинают переходить в более мелкие классы - 5-10 мкм и $<5$ мкм.

Объяснить селективность распределения разрушенных частиц по размерам можно с позиций механизма образования исходных частиц конверсионного карбоната кальция. Конверсионный карбоната кальция представляет собой поликристаллические агрегаты, полученные по механизму полинуклеарной массовой кристаллизации. Совокупная прочность частиц, а значит и работа, требуемая на их разрушение, будут определяться как энергией кристаллической решетки кальцита, так и дефектностью внутренней структуры агрегатов и, прежде всего в местах срастания первичных кристаллитов. С увеличением линейных размеров частиц дефектность и неупорядоченность структуры будут возрастать, а требуемые энергетические затраты на разрушение, соответственно, снижаться. Это, повидимому, и определяет большую скорость диспергирования для более крупных частиц, наблюдаемую экспериментально при виброизмельчении конверсионного карбоната кальция. В свою очередь, разрушение кристаллитов требует значительно больших затрат энергии, чем на разрушение исходных агломератов, что можно предположить из их меньшей дефектности. В использованном типе измельчающего оборудования - ролико-кольцевой вибрационной мельнице с заданной мощностью и производительностью разрушение кристаллитов идет со значительно меньшей скоростью, чем агрегатов, что обуславливает нижний предел дисперсности измельченного карбоната кальция на уровне размеров кристаллитов ( $<5$ мкм), а также придает бимодальность распределению частиц измельченного продукта по размерам.

Кроме селективности измельчения характер полученных закономерностей изменения дисперсного состава показывает, что виброизмельчение конверсионного карбоната кальция является обратимым процессом - при продолжительности более 5 минут происходит заметное агломерирование частиц, что вызывает снижение содержания более мелких фракций в получаемом продукте. Так, при 5 минутах начинает происходить снижение содержания частиц размером $<5$ мкм, при 10 минутах $-5-$ 
10 мкм. Размер получаемых при агломерировании частиц лежит в интервале 10-30 мкм, что приводит заметному увеличению содержания классов 10-20 и 20-30 мкм после 5-10 минут измельчения.

Интенсивность процесса агломерирования, как следует из полученных данных, возрастает с увеличением времени нахождения материала в мельнице. Прочность образованных агломерированных структур достаточно высока, так как не обнаруживалось их разрушения при диспергировании в воде при выполнении анализа дисперсного состава методом лазерной дифракции и характер распределения частиц по размерам не претерпевает изменения.

Причиной агломерирования является, по-видимому, повышение избыточной поверхностной энергии с ростом дисперсности разрушенных частиц и соответственное возникновение когезионного взаимодействия между вновь сформированными поверхностями. На протекание процесса агломерирования при продолжительном измельчении как сухим, так и мокрым способом на различных типах измельчающего оборудования указывается в значительном числе работ для разнообразных материалов природного и техногенного происхождения [2-4]. Тонкое измельчение природного карбоната кальция также может сопровождаться агломерированием разрушенных частиц. Так, в работе [5] отмечается существенная роль процесса образования агломератов на кинетические закономерности и эффективность мокрого помола природного кальцита в шаровой мельнице. Агломерирование частиц при продолжительном измельчении является важным технологическим фактором, который необходимо учитывать при осуществлении тонкого помола конверсионного карбоната кальция на промышленном измельчающем оборудовании.

Основным кинетическим законом теории диспергирования твердых материалов является то, что скорость измельчения пропорциональна массе недоизмельченного продукта, находящегося в данный момент времени в мельнице [6]. Процесс диспергирования может рассматриваться аналогично протеканию обычной химической реакции, в котором крупные частицы измельчаемого материала «реагируют» с образованием мелких частиц разрушенного материала. Эмпирическое уравнение кинетики измельчения выражается уравнением:

$$
d R_{i}(\tau) / d \tau=k_{i} \cdot\left[R_{i}(\tau)\right]^{n},
$$

где $R_{\mathrm{i}}(t)$ - масса недоизмельченного продукта в момент $\tau$ крупностью $i ; \tau-$ продолжительность измельчения; $k_{i}$ - удельная скорость измельчения; $n$ - порядок процесса.

Если величина $k_{i}$ не зависит от продолжительности измельчения и кинетика измельчения подчиняется первому порядку, то уравнение (1) можно представить в линейной форме:

$$
\ln \left[R_{i}(\tau) / R_{i}(0)\right]=-k_{i} \cdot \tau,
$$

где $R_{i}(0)$ - масса исходного продукта крупностью $i$.

В этом случае, при соответствии наблюдаемого процесса измельчения первому порядку, изменение дисперсного состава измельчаемого материала в полулогарифмических координатах будет изображаться прямой линией с угловым коэффициентом, равным $k_{i}$.

По смыслу и численно $k_{i}$ соответствует селективной функции $S_{i}$ в модели кинетики измельчения, предложенной для описания процесса измельчении различных материалов в шаровых, вибрационных мельницах, когда одиночные частицы разрушаются стесненным или свободным ударом [7]:

$$
d R_{i}(\tau) / d \tau=\left[\sum_{j-1}^{i-1} S_{j} \cdot R_{j}(\tau) \cdot b_{i l}\right]-S_{j} \cdot R_{j}
$$

В уравнении селективная функция $S_{\mathrm{i}}\left(S_{\mathrm{j}}\right)$ определяет интенсивность разрушения частиц соответственно крупностью $i$ и $j$ в единицу времени. Распределительная функция $b_{i j}$, в свою очередь, показывает долю частиц размером $j\left(R_{j}\right)$, которые после разрушения перешли в фракцию с размером частиц $i$.

Применение уравнения кинетики первого порядка для оценки скорости сухого и мокрого помола различных материалов природного и техногенного происхождения в различных типах мельниц ударноистирающего действия широко описано в литератуpe [7-10]. Тонкое измельчение природного карбоната кальция также часто подчиняется уравнению кинетики первого порядка $[4,5]$. Для конверсионного карбоната кальция такая информация не найдена.

Так как величина $k_{i}$ зависят от размера частиц [7], то экспериментально значения удельной скорости измельчения определяли для узких фракций: 45-63; 63-100; 100-160 мкм в ограниченном интервале времени 0-5 мин с шагом 30 с, что соответствует периоду интенсивного разрушения частиц карбоната кальция в принятых условиях измельчения. Фракции предварительно выделялись из исходной пробы продукта на ситах с соответствующим размером ячеек.

Полученные кинетические кривые измельчения конверсионного карбоната кальция по задан- 
ным фракциям, выраженные в полулогарифмических координатах уравнения (2) представлены на рис. 1.

Как видно из полученных результатов, кинетика измельчения конверсионного карбоната кальция в вибрационной мельнице подчиняется уравнению первого порядка - наблюдается линейная зависимость между относительным содержанием неизмельченных фракций $\ln \left[R_{d}(t) / R_{d}(0)\right]$ и временем измельчения $t$.

Полученные расчетные значения удельной скорости измельчения $k$ и коэффициенты корреляции $R^{2}$ представлены в табл. 3 .

Зависимость удельной скорости измельчения $k$ от размера частиц конверсионного карбоната кальция для исследованных фракций может быть описана уравнением [7]:

$$
k_{i}=a \cdot X_{i}^{\alpha}
$$

где: $X_{i}$ - максимальный размер частиц в фракции $i$; $a, \alpha$ - модельные коэффициенты, зависящие от свойств материала и условий измельчения.

Полученная зависимость представлена на рис. 2 и выражается (при $\left.R^{2}=0.994\right)$ уравнением:

$$
k_{i}=0.0391 \cdot X^{0,634} .
$$

Оценка адекватности модели (4) показала удовлетворительную сходимость, среднеквадратическая ошибка не превышает $10 \%$.

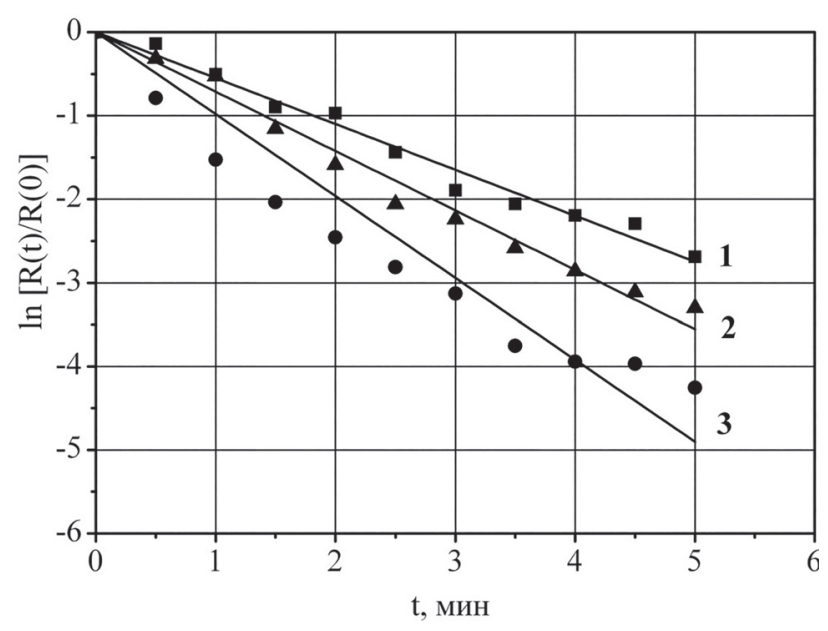

Рис. 1. Зависимость изменения фракционного состава $R_{\mathrm{d}}$ : 45-63 мкм (1), 63-100 мкм (2), 100-160 мкм (3) от продолжительности измельчения $(t)$ конверсионного карбоната кальция

[Fig. 1. Dependence of the change in the fractional composition of $R_{\mathrm{d}}: 45-63 \mu \mathrm{m}(1), 63-100 \mu \mathrm{m}(2), 100-$ $160 \mu \mathrm{m}(3)$ on the duration of grinding $(t)$ of conversion calcium carbonate]
Таблица 3. Константа скорости измельчения $(k)$ конверсионного карбоната кальция

[Table 3. Rate constant of grinding $(k)$ conversion calcium carbonate]

\begin{tabular}{|c|c|c|}
\hline $\begin{array}{c}\text { Фракция, } \\
\text { мкм } \\
\begin{array}{c}\text { Fraction, } \\
\mu \mathrm{m}]\end{array}\end{array}$ & $\begin{array}{c}\text { Удельная скорость } \\
\text { изельчения } k, \text { мин }^{-1} \\
\text { [Specific speed of } \\
\text { grinding } k, \mathrm{~min}^{-1} \text { ] }\end{array}$ & $\begin{array}{c}\text { Коэффициент } \\
\text { Корреляции, } R^{2} \\
\text { [Coefficient } \\
\text { correlations, } R^{2} \text { ] }\end{array}$ \\
\hline $45-63$ & $0.549 \pm 0.013$ & 0.981 \\
\hline $63-100$ & $0.711 \pm 0.016$ & 0.982 \\
\hline $100-160$ & $0.980 \pm 0.044$ & 0.906 \\
\hline
\end{tabular}

\section{ВЫВОДЫ}

Тонкому измельчению конверсионного карбоната кальция в вибрационной мельнице присущи характерные особенности, заключающиеся в следующем:

1. Общая скорость измельчения лимитируется содержанием средних фракций исходного продукта: 50-75, 75-100, 100-150 мкм; изменение их содержания, в целом, происходит пропорционально возрастанию времени протекания процесса. Измельчение частиц размером 150-200 мкм и $>200$ мкм идет значительно медленнее из-за большей прочности зерен нерастворимого остатка.

2. Процесс измельчения является избирательным по размеру продуктов разрушения - предпоч-

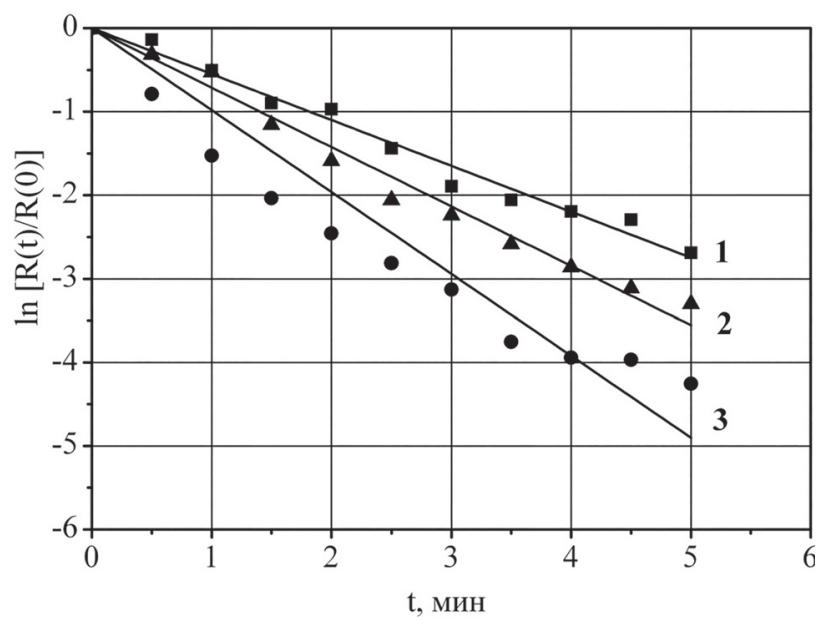

Рис. 2. Зависимость изменения удельной скорости измельчения $(k)$ от максимального размера частиц измельчаемых фракций $(X)$

[Fig. 2. Dependence of the change in the specific grinding speed $(k)$ on the maximum particle size of the grindable fractions $(X)$ ] 
тительно, после диспергирования частицы переходят в фракцию $<5$ мкм, и в меньшей степени в фракции 5-10, 10-20, 20-30 мкм, вследствие чего распределение приобретает бимодальный характер.

3. Длительное измельчение является обратимым и приводит к агломерированию наиболее дисперсных частиц, размер образующихся достаточно прочных агломератов находится в интервале 10-30 мкм.

4. Кинетика измельчения следует уравнению первого порядка, удельная скорость измельчения конверсионного карбоната кальция существенно возрастает при увеличении размера частиц.

\section{СПИСОК ЛИТЕРАТУРЫ}

1. Рудакова Л. В., Нифталиев С. И., Натарова Е. С. // Изв. вузов. Химия и хим. технология. 2017, т. 60, № 4, c. 100-107. DOI: http://dx.doi.org/10.6060/ tcct.2017604.5547

2. Brecevic L., Nothig-Laslo V., Kralj D. // Journal of the Chemical Society, 1996, vol. 6, № 92, pp. 1017-1022.
3. Tai C. Y., Chen P. C. AIChE Journal, 1995, vol. 1, № 41, pp. 68-77.

4. Sedlatschek K., Bass L // Powder Metall. Bull, 1953, vol. 6, pp. 148-153.

5. Arbiter N., Bhrany U. N. // American Institute of Mining and Metallurgical Engineers, 1960, vol. 217, pp. 245-252.

6. Островский Г. М. Новый справочник химика и технолога. Прочессы и аппараты химических технологий. Ч. 1. Санкт-Петербург, АНО НПО «Профессионал», 2004, 848 с.

7. Сиденко П. М. Измельчение в химической промылиленности. М.: Химия, 1977, 368 с.

8. Ревнивцев В. И. Вибрациионная дезинтеграция твердых материалов. М.: Недра, 1992, 430 с.

9. Авдохин В. М. Основы обогащчения полезных ископаемыхx. T. 2. М.: Издательство МГУ, 2006, 417 с.

10. Андреев С. Е., Товаров В. В., Перов В. А. Закономерности измельчения и исчисление характеристик гранулометрического состава. М.: Государственное научно-техническое издательство литературы по черной и цветной металлургии, 1959, 437 с.

\title{
KINETICS AND THE MECHANISM OF CHEMICALLY-DEPOSITED CALCIUM CARBONATE GRINDING
}

\author{
(C) 2018 L. V. Rudakova ${ }^{1}$, S. I. Niftaliev ${ }^{2}$, E. S. Natarova ${ }^{1}$
}

${ }^{1}$ Voronezh State Medical University named after N. N. Burdenko, 10 Studencheskaya str., 394036 Voronezh, Russia Voronezh State University of Engineering Technologies, 19 Revolution ave., 394036 Voronezh, Russia e-mail: natarovaekaterina@yandex.ru

Received 21.02.2018

\begin{abstract}
Conversion calcium carbonate is a by-product of manufacturing mineral fertilizers, i.e. NAP fertilizer. It needs further processing and grinding to be used as a filler for polymeric materials. The choice of equipment and the final degree of grinding depend on the kinetic characteristics of the process. The aim of the work is to study the mechanism and kinetics of chemically-deposited calcium carbonate grinding. The feedstock was ground by means of a laboratory vibratory mill for 30 minutes, a sample was taken every minute to study the fractional composition and the speed of the process. It was determined that the most intensive processing takes place during the first minute of grinding $(t=0-1 \mathrm{~min})$, the maximum grinding speed is reached for fractions of $+50-75 \mu \mathrm{m}$, $+75-100 \mu \mathrm{m}$, and $+100-150 \mu \mathrm{m}$ and are $14.5 \% / \mathrm{min}, 13.5 \% / \mathrm{min}$ and $17.5 \% / \mathrm{min}$ respectively. Particles predominantly fall into the grade of $-5 \mu \mathrm{m}$, and, to a lesser extent, into the classes $+5-10 \mu \mathrm{m}$, $+10-20 \mu \mathrm{m}$, and $+20-30 \mu \mathrm{m}$, resulting in a bimodal distribution. With an increase in processing time by more than 5 minutes, the agglomeration of particles occurs, the size of which ranges 10-30 $\mu \mathrm{m}$. The grinding kinetics of the chemically-deposited calcium carbonate obeys the rules of a first-order equation. A linear relationship is observed between the relative content of the unground fractions $\ln [\operatorname{Rd}(\mathrm{t}) / \operatorname{Rd}(0)]$ and the grinding time $t$. The specific grinding speed of conversion calcium carbonate increases significantly with an increase in particle size.
\end{abstract}

Keywords: conversion calcium carbonate, grinding, process speed, kinetics.

DOI: https://doi.org/10.17308/kcmf.2018.20/516 


\section{REFERENCES}

1. Rudakova L. V., Niftaliev S. I., Natarova E. S. Izv. Vyssh. Uchebn. Zaved. Khim. Khim. Tekhnol. 2017, vol. 60, no. 4, pp. 100-107. DOI: http://dx.doi.org/10.6060/ tcct.2017604.5547 (in Russ.)

2. Brecevic L., Nothig-Laslo V., Kralj D. Journal of the Chemical Society, 1996, vol. 6, no. 92, pp. 1017-1022.

3. Tai C. Y., Chen P. C. AIChE Journal, 1995, vol. 1, no. 41, pp. 68-77.

4. Sedlatschek K., Bass L. Powder Metall. Bull, 1953, vol. 6, pp. 148-153.

5. Arbiter N., Bhrany U. N. American Institute of Mining and Metallurgical Engineers, 1960, vol. 217, pp. 245252.

6. Ostrovskii G. M. Novyi spravochnik khimika i tekhnologa. Protsessy i apparaty khimichekikh tekhnologii pt. 1 [A New Directory of Chemist and Technologist. Processes and Apparatus of Chemical Technologies. Part 1.], St. Pe- tersburg, ANO NPO «Professional» Publ., 2004, 848 p. (in Russ.)

7. Sidenko P. M. Izmel'chenie v khimicheskoi promyshlennosti [Crushing in the Chemical Industry], Moscow, Khimiya Publ., 1977, 368 p.

8. Revnivtsev V. I. Vibratsionnaya dezintegratsiya tverdykh materialov [Vibration Disintegration of Solid Materials], Moscow, Nedra Publ., 1992, 430 p. (in Russ.)

9. Avdokhin V. M. Osnovy obogashcheniya poleznykh iskopaemykh [Basics of Mineral Processing. Pt. 2. Moscow: MSU Publishing House, 2006, 417 p. (in Russ.)

10. Andreev S. E., Tovarov V. V., Perov V. A. Zakonomernosti izmel'cheniya i ischislenie kharakteristik granulometricheskogo sostava [Regularities of Grinding and Calculation of Characteristics of Granulometric Composition]. Moscow, Gosudarstvennoe nauchno-tekhnicheskoe izdatel'stvo literatury po chernoi i tsvetnoi metallurgii [State scientific and technical publishing house of literature on ferrous and nonferrous metallurgy] Publ., 1959, 437 p. (in Russ.)
Рудакова Людмила Васильевна - д. х. н., доцент, заведующая кафедрой фармацевтической химии и фармацевтической технологии, Воронежский государственный медицинский университет им. Н. Н. Бурденко; тел.:+7(473) 2530249, e-mail: pharmchem.vgma@mail.ru

Нифталиев Сабухи Ильич-д. х. н., профессор, заведующий кафедрой неорганической химии и химической технологии, Воронежский государственный университет инженерных технологий; тел.: +7(473) 2553887, e-mail: sabukhi@gmail.com

Натарова Екатерина Сергеевна - ассистент, кафедра фармацевтической химии и фармацевтической технологии, Воронежский государственный медицинский университет им. Н. Н. Бурденко; тел.:+7(473)2530249, e-mail: natarovaekaterina@ yandex.ru
Lyudmila V. Rudakova-Dr. Sci. (Chem.), Assistant Professor, Head of the Department of Pharmaceutical Chemistry and Pharmaceutical Technology, Voronezh State Medical University N.N. Burdenko; tel.: +7(473) 2530249, e-mail: pharmchem.vgma@mail.ru

Sabukhi I. Niftaliev - Dr. Sci. (Chem.), Professor, Head of the Department of Inorganic Chemistry and Chemical Technology, Voronezh State University of Engineering Technologies; tel.: +7(473) 2553887, email: sabukhi@gmail.com

Ekaterina S. Natarova-Assistant, Department of Pharmaceutical Chemistry and Pharmaceutical Technology, Voronezh State Medical University N. N. Burdenko; tel.: +7(473) 2530249, e-mail: natarovaekaterina@yandex.ru 